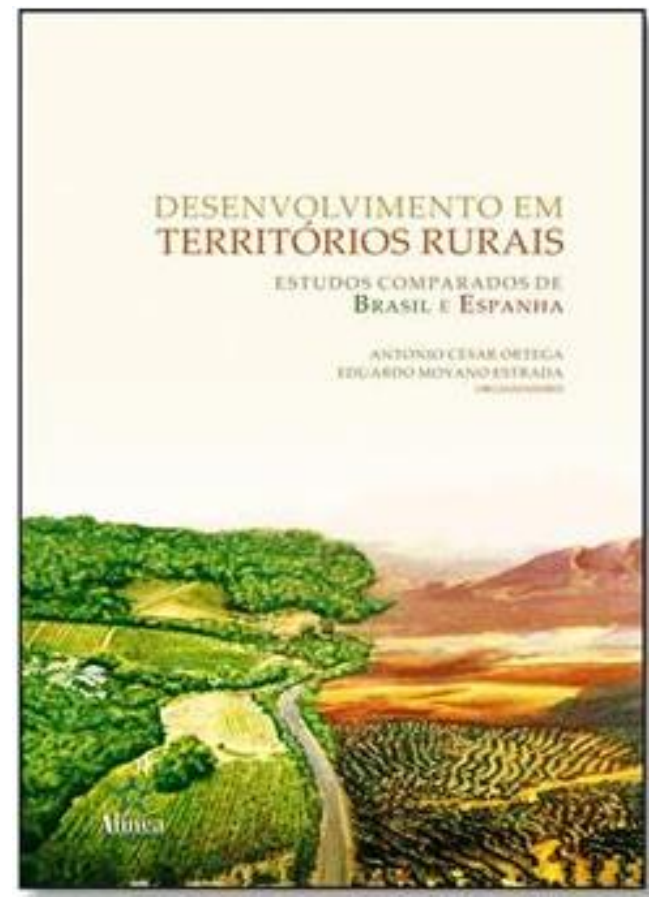

\title{
Resenha
}

\section{Desenvolvimento em Territórios Rurais: estudos comparados de Brasil e Espanha}

Ortega, A. C.; Moyano-Estrada, E. (Org.). Desenvolvimento em Territórios Rurais: estudos comparados de Brasil e Espanha. 1. ed. Campinas: Alínea, 2015. v. 1. 434p

Bruno Benzaquen Perosa*

\section{Introdução}

Não é incomum que algumas abordagens teóricas de grande relevância se tornem tão populares que seu uso acabe de certa forma banalizado na academia e no debate público. Esse parece ser o caso do enfoque territorial, cujo modismo e o uso indiscriminado e impreciso nos últimos anos deturparam parte de seu sentido. Contudo, trabalhos acadêmicos sérios e cuidadosos podem e devem corrigir esse desvio ao fazer uso rigoroso dessa metodologia para entender os principais entraves ao desenvolvimento regional. Essa é justamente a proposta da coletânea Desenvolvimento em Territórios Rurais, organizado por Antonio Cesar Ortega e Eduardo Moyano Estrada.

Resultado de uma parceria duradoura entre os organizadores, formalizada nos últimos anos no âmbito do projeto interinstitucional (IE-UFU no Brasil e CSIC na Espanha) “Desenvolvimento em Territórios Rurais: estudos comparados de Brasil e Espanha" com

*Professor do Instituto de Economia da Universidade Federal de Uberlândia (UFU). E-mail: brunoperosa@ie.ufu.br 
financiamento do CNPQ, o livro apresenta uma ampla gama de experiências sobre o desenvolvimento em territórios da Europa e do Brasil. A própria estrutura do livro demonstra como essa parceria vem gerando a disseminação dessa abordagem no Brasil, dado que grande parte dos capítulos é assinada por pós-graduandos que aplicaram esse enfoque em suas teses e dissertações.

O livro busca explorar diversas dimensões do desenvolvimento a partir do enfoque territorial. O trabalho já se inicia apresentando uma conceituação do enfoque territorial e das categorias de territórios analisados. A distinção entre territórios induzidos por políticas públicas daqueles constituídos autonomamente é fundamental para compreender a diversidade de arranjos territoriais que esse aporte permite analisar, o que ficará evidente ao longo dessa obra. Apesar da abordagem do livro estar mais voltada ao mundo rural, os autores não incorrem no erro de analisar esse setor em separado dos demais setores econômicos. A interação do rural com atividades urbanas é sempre considerada.

Do ponto de vista teórico, observa-se uma vasta gama de abordagens que dão sustentação à análise territorial. Os aportes oriundos do neo-institucionalismo permitem o entendimento de elementos relevantes do ambiente institucional e organizacional. Também fica evidente uma prolífica interação da visão territorial com a abordagem da nova economia institucional, cuja aplicação mais conhecida é utilizada para explicar o desenvolvimento de nações.

Dentre os inúmeros conceitos relacionados à questão territorial, observa-se um cuidado especial nas singularidades que diferenciam os territórios e que acabam por constituir o eixo central dessa abordagem. A identificação dessas especificidades de cada território é fundamental para construção de estratégias públicas e privadas que permitam uma articulação entre os diferentes atores. Nesse sentido, a construção de bons mecanismos de governança e gestão dos recursos disponíveis se mostra como um dos principais entraves ao desenvolvimento.

\section{Estrutura da coletânea}

A coletânea é composta por 16 capítulos, divididos em 5 partes. Na primeira parte, de cunho mais histórico, os organizadores se dedicam a uma explanação mais geral sobre as políticas territoriais no Brasil e na Europa, de forma a dar um panorama geral da atuação do Estado e seus impactos sobre as diversas experiências que serão apresentadas nos capítulos seguintes. Assim, o primeiro capitulo assinado por Antonio César Ortega apresenta as políticas 
territoriais implementadas no Brasil a partir de meados da década de 1990. O capitulo explora a forma "isolada" que estas eram implantadas até 2003, quando passam a compor um conjunto mais amplo de políticas sob coordenação do governo federal. O segundo capítulo, de Eduardo Moyano, aborda o caso europeu considerando tanto as políticas nacionais aplicadas na Espanha e na Região da Andaluzia, como as políticas implantadas a partir de 1991 no âmbito da União Europeia. A experiência Europeia é detalhada desde o projeto Leader até os dias atuais, evidenciando a interação com as políticas locais que já vinham sendo adotadas anteriormente.

Na segunda parte são apresentados 4 capítulos de cunho teórico e metodológico, onde são discutidos elementos relevantes para compreensão do enfoque territorial. $\mathrm{O}$ capitulo 3 de autoria de Eduardo Moyano Estrada analisa a questão da governança nos espaços territoriais. $\mathrm{O}$ autor ilustra bem as dificuldades encontradas por gestores locais em aplicar recursos públicos de forma a complementar os investimentos privados na construção de uma dinâmica territorial prolífica. Conseguir suplantar interesses privados (tanto de atores públicos como privados) aparece como o maior desafio na construção de tais políticas. Já o quarto capítulo, de autoria de Fernando Garrido Fernandez, José Gomes Limón e Esperanza Vera Toscano, apresenta uma discussão aprofundada sobre a teoria do capital social, que permeia boa parte do enfoque territorial. A discussão evidencia a dificuldade de mensurar a existência dessa forma de capital e, consequentemente, de verificar os entraves para o desenvolvimento territorial. O capítulo 5, de autoria de Daniel Lemos Jeziorny, avança na discussão acerca da relação entre política e inovação tecnológica. $\mathrm{O}$ autor enfatiza a necessidade de se construir um sistema de inovação eficaz que premie aqueles que inovam e ao mesmo tempo permita a difusão desse conhecimento para os demais atores do território. No sexto capitulo, que fecha a seção 2 da coletânea, escrito por Debora Nayar Hoff, Clésio Marcelino de Jesus e Antonio Cesar Ortega, discute-se a intrincada construção de "marcas" ligadas aos territórios. Os autores exploram a importância mercadológica de se garantir o reconhecimento de características intrínsecas de uma região. Também são destacadas as dificuldades em se obter o reconhecimento das Indicações de Procedência (IP), que demandam organização dos atores presentes nos territórios.

A terceira parte do livro é composta por 7 estudos de casos relatando experiências de regiões na busca pelo desenvolvimento. No primeiro capítulo dessa parte e sétimo do livro, Eduardo Moyano Estrada narra a experiência da Espanha e da Andaluzia, considerando como as políticas territoriais foram implementadas de forma a combater problemas econômicos e sociais desses territórios. $\mathrm{O}$ autor inicia descrevendo como tais políticas foram integradas a um programa de reformas mais profundo visando acelerar o desenvolvimento espanhol. A seguir é 
apresentado o caso andaluz, um território em que a agricultura familiar sempre teve papel central. Moyano narra as estratégias que foram implementadas visando melhorar a governança entre produtores por meio de cooperativas, sendo estas complementadas por ações visando valorizar os produtos e vinculá-los aos territórios. O capítulo 8, de autoria de Clésio Marcelino de Jesus, apresenta uma interessante comparação entre territórios na Espanha e no Brasil. De forma a facilitar a comparação dos territórios e de sua trajetória, o autor utiliza a já mencionada divisão entre territórios constituídos autonomamente (Café do Cerrado Mineiro e Los Pedroches) e aqueles induzidos por políticas públicas (Noroeste de Minas; Medio Guadalquivir e Guadajoz y Campina Este de Córdoba). O capítulo 9, assinado por Daniel Lemos Jeziorny explora o uso das indicações geográficas como uma forma de tecnologia que permite a apropriação de espaços para obtenção de rendas extraordinárias. De forma a observar como esse processo pode gerar resultados distintos a depender da forma como é coordenado por associações locais, o autor analisou experiências no Brasil (Vale dos Vinhedos) e na Espanha (Montilla-Moriles). O capítulo 10, autorado por Eduardo Magalhaes Ribeiro, Flavia Maria Galizoni, Camila da Silva Freitas, Viviane Guimaraes Pereira, Ana Luiza Caldas e Mariana de Oliveira Santos, analisou algumas experiências de territórios induzidos por políticas no estado de Minas Gerais. Os autores deixam clara a importância e a dificuldade dessas políticas em construir dinâmicas de desenvolvimento em regiões com baixos níveis de desenvolvimento e organização produtiva. Já o capítulo 11, assinado por Antonio Cesar Ortega e Clésio Marcelino de Jesus, aprofunda essa análise nos territórios induzidos por políticas públicas em Minas Gerais, considerando que elementos distinguem experiências de políticas públicas bem e malsucedidas. No capítulo 12, Felipe Prado Macedo da Silva, prossegue na análise de territórios induzidos por políticas públicas, apresentando um estudo de caso do território do Sisal, na Bahia. Esse capitulo ressalta a questão da heterogeneidade em territórios muito vastos ou mal definidos, considerando as características econômicas, sociais e culturais das regiões. $\mathrm{O}$ autor enfatiza a importância de uma boa delimitação territorial para obter melhores resultados. Por fim, no capitulo 14, que encerra essa terceira parte do livro, Flavio Sacco dos Anjos, Fernanda Novo da Silva e Jimena Gonzáles Ruís exploram outro instrumento relevante para o desenvolvimento territorial, a denominação de origem (DO). Considerando a experiência da Andaluzia, os autores discutem a dificuldade de governança nos conselhos gestores que coordenam as DOs, devido à heterogeneidade de produtores e interesses entre estes. Os autores lançam luz sobre o problema da exclusão de segmentos produtivos e da competição entre certificações em regiões próximas. 
A quarta parte do livro se inicia apresentando um tema relevante para formação da identidade territorial, os esportes de natureza e de aventura. Assim, no capítulo 14, David Moscoso Sanches explora a importância de modalidades lúdicas e recreativas, o que também pode ser extrapolado para outras atividades que explorem a imagem do território, como o eco ou agro turismo, tanto como forma de divulgar a história e a cultura dos territórios como uma atividade econômica complementar. O capítulo 15, assinado por Esperanza Vera-Toscano, busca analisar a experiência do desenvolvimento territorial pela ótica feminina, grupo social diretamente afetado pelas transformações observadas em alguns territórios. A relativa "vulnerabilidade econômica" desse grupo e sua importância para construção social são exploradas pela autora, considerando uma dimensão pouco usual do enfoque territorial.

$\mathrm{Na}$ quinta e última parte do livro, Antonio Cesar Ortega apresenta um balanço das principais conclusões apresentadas ao longo do livro e das experiências dos pesquisadores envolvidos ao longo do já mencionado projeto interinstitucional Desenvolvimento Territorial Rural: Estudo comparado entre Brasil-Espanha.

Apesar de seguir uma estrutura pouco linear, o livro consegue uma boa amarração dos conceitos, mesclando análise histórica e teórica com estudos de caso, que geralmente aplicam parte do referencial apresentado previamente. Dessa forma, mesmo o leitor mais leigo na abordagem territorial pode absorver os conceitos e assim compreender a análise empírica detalhada nos capítulos seguintes. O resultado é uma obra bastante didática e relevante para aqueles que buscam saber mais sobre o enfoque territorial e suas aplicações. Dessa forma, o livro é de grande utilidade para acadêmicos e para aqueles envolvidos no desenho de políticas públicas, especialmente ligadas ao universo rural. 